\title{
Automaattimittauksilla tarkkaa tietoa maatalouden vesistökuormituksesta
}

\author{
Pasi Valkama, Kirsti Lahti ja Asko Särkelä \\ Vantaanjoen ja Helsingin seudun vesiensuojeluyhdistys ry \\ Asemapäällikönkatu 12 C, 00520 Helsinki, \\ etunimi.sukunimi@vesiensuojelu.fi
}

Tässä tutkimuksessa esitellään Vantaanjoen ja Helsingin seudun vesiensuojeluyhdistyksen käyttämä automaattiseen veden laadun seurantaan perustuva menetelmä, jolla saadaan uutta ja tarkempaa tietoa maatalousvaltaisten valuma-alueiden kuormitusprosesseista. Tutkimuksessa seurattiin kahden pintaalaltaan erikokoisen, peltovaltaisen valuma-alueen veden laatua jatkuvatoimisesti automaattisilla mittausantureilla. Lepsämänjoen valuma-alueella sijaitsevassa pienessä pelto-ojassa $\left(2,7 \mathrm{~km}^{2}\right)$ mittauksia tehtiin kevään ja syksyn ylivirtaamakausina 2005-2009. Lepsämänjoen yläosan valuma-alueella (23 $\mathrm{km}^{2}$ ) on tehty yhtäjaksoisia mittauksia huhtikuusta 2006 alkaen.

Mittausasemilla seurattiin veden laatua pääasiassa tunnin aikavälillä. Tärkeimmät mitatut muuttujat olivat sameus, sähkönjohtokyky ja nitraattipitoisuus. Anturin mittaaman sameuden ja laboratoriomääritysten väliseen erittäin merkitsevään korrelaatioon perustuen veden kokonaisfosfori- ja kiintoainepitoisuus voitiin laskea mittaustaajuuden mukaisesti. Kaikki mittausdata lähetettiin aseman lähetinyksikön avulla palvelimelle, josta se oli ladattavissa internetin välityksellä. Virtaama laskettiin mittauspaikoille laadittujen purkautumiskäyrien ja vedenkorkeustiedon avulla.

Tulosten perusteella voitiin todeta pelloilta huuhtoutuvan kuormituksen syntyvän hyvin nopeina pulsseina lähinnä kevään lumensulamisjaksojen ja syksyn sadejaksojen aikana. Koska kuormitustapahtumat olivat hyvin nopeita, ei yksittäisten näytteiden perusteella saatu todellista veden laadun vaihtelua selville. Tällä on merkitystä erityisesti ravinnekuormia laskettaessa. Jatkuvatoimisella automaattiseurannalla saatiinkin kuormituksesta paljon tarkempi kuva kuin yksittäisten näytteiden perusteella.

Lepsämänjoen kiintoaine- ja fosforikuormia nostivat myös leutojen talvien aikaiset sateet ja useat lyhyet lumensulamisjaksot. Esimerkiksi lauha, sateinen talvi 2008 johti hankalan kuormitusjakson jatkumiseen lähes yhtenäisenä syksystä aina kevättulvaan saakka. Ilmastonmuutoksen myötä leudontuvat talvet näyttäisivät lisäävän maataloudesta tulevaa ravinnekuormitusta huomattavasti.

Fosfori- ja typpikuormituksen havaittiin muodostuvan maatalousvaltaisissa virtavesissä eri tavoin. Tulvatilanteessa fosforipitoisuuden maksimi saavutettiin ennen virtaamahuippua. Fosforikuormitus syntyy suurimmaksi osaksi peltojen pintavalunnan ja salaojien kautta vesistöön huuhtoutuvan kiintoaineen mukana. Uomissa mitatut korkeat fosforipiikit muodostuvat tämän kiintoaineen lähtiessä liikkeelle uoman pohjasta tulvan nousuvaiheessa. Nitraattipitoisuus taas nousi maksimiinsa säännöllisesti vasta virtaamahuipun jälkeen. Typpikuorma syntyy lähinnä salaojien kautta tulevana huuhtoumana.

Asiasanat: automaattinen veden laadun seuranta, maatalouden vesistökuormitus, ilmastonmuutos 


\section{Johdanto}

Jatkuvatoimisesti veden laatua mittaavat automaattiset anturit ovat osoittautuneet erinomaiseksi välineeksi selvitettäessä nopeita veden laadussa tapahtuvia muutoksia (Valkama ym. 2007 ja Valkama ym. 2008). Mittaustekniikan kehittyminen on tehnyt tarkat ja luotettavat mittaukset mahdollisiksi suoraan vesistöistä. Maatalouden kuormitusseurantaa on perinteisesti tehty vesistönäytteistä määritettyjen yksittäisten ravinnepitoisuuksien ja virtaamatietojen perusteella (mm. Nykänen 1991; Leinonen 1992; Lehtinen ym. 1993; Räike ym. 2004). Veden laadussa tapahtuvat muutokset ovat kuitenkin niin nopeita, että yksittäisten näytteiden avulla todellista vaihtelua ei voida havaita.

Vantaanjoen ja Helsingin seudun vesiensuojeluyhdistyksessä aloitettiin vuoden 2005 syksyllä automaattisten veden laatua seuraavien mittausantureiden koekäyttö savisameissa Vantaanjoen valuma-alueen virtavesissä (Särkelä ym. 2006). Tutkimuksen tulokset olivat lupaavia ja ensimmäistä kertaa saatiin tarkkoja arvioita maatalouden hajakuormasta mittausantureiden avulla. Tutkimuksessa seurattiin kahden erikokoisen peltovaltaisen valuma-alueen veden laatua jatkuvatoimisesti automaattisilla mittausantureilla. Lepsämänjoen valuma-alueella sijaitsevassa pienessä pelto-ojassa $\left(2,7 \mathrm{~km}^{2}\right)$ mittauksia tehtiin kevään ja syksyn ylivirtaamakausina 2005-2009. Lepsämänjoen yläosan valuma-alueella $\left(23 \mathrm{~km}^{2}\right)$ mittauksia tehtiin syksyllä 2005 ja edelleen yhtäjaksoisesti vuoden 2006 huhtikuusta alkaen.

Tähän tutkimukseen valittiin Lepsämänjoen ja pelto-ojan pitkistä automaattimittaussarjoista esimerkkijaksoja joiden avulla selvitettiin erityisesti automaattisten mittausantureiden tuomaa hyötyä suhteessa perinteiseen kuormitusseurantaan, talvien leudontumisen vaikutuksia hajakuormitukseen sekä tarkemmin kuormituksen muodostumista uomissa.

\section{Aineisto ja menetelmät}

Mittausasemat koostuivat YSI:n multiparametrisista antureista, joilla mitattiin tunnin välein veden sameutta, lämpötilaa, sähkönjohtokykyä ja lämpötilaa. Mekaanisen pyyhkimen omaavan optisen sameussensorin mittausperiaate vastasi laboratoriossa tehtyjä sameusmittauksia. Sensorissa on valonlähteenä ledi, joka mittauksessa lähettää valoa optista kuitua pitkin mitattavaan vesimassaan. Veteen suspendoituneista hiukkasista siroavaa valoa mittaa erillinen detektori, joka on 90 asteen kulmassa valonlähteeseen nähden. Keväästä 2007 alkaen ylivirtaamajaksojen mittauksia täydennettiin Scanin UV-VIS spektrometriaan perustuvilla antureilla, jolla mitattiin veden nitraattipitoisuutta ja liukoisen orgaanisen hiilen pitoisuutta. Kaikki mittausdata lähetettiin aseman lähetinyksikön avulla palvelimelle, josta se oli ladattavissa internetin välityksellä. Vedenkorkeuden reaaliaikaiseen seurantaan käytettiin erillistä paineanturia.

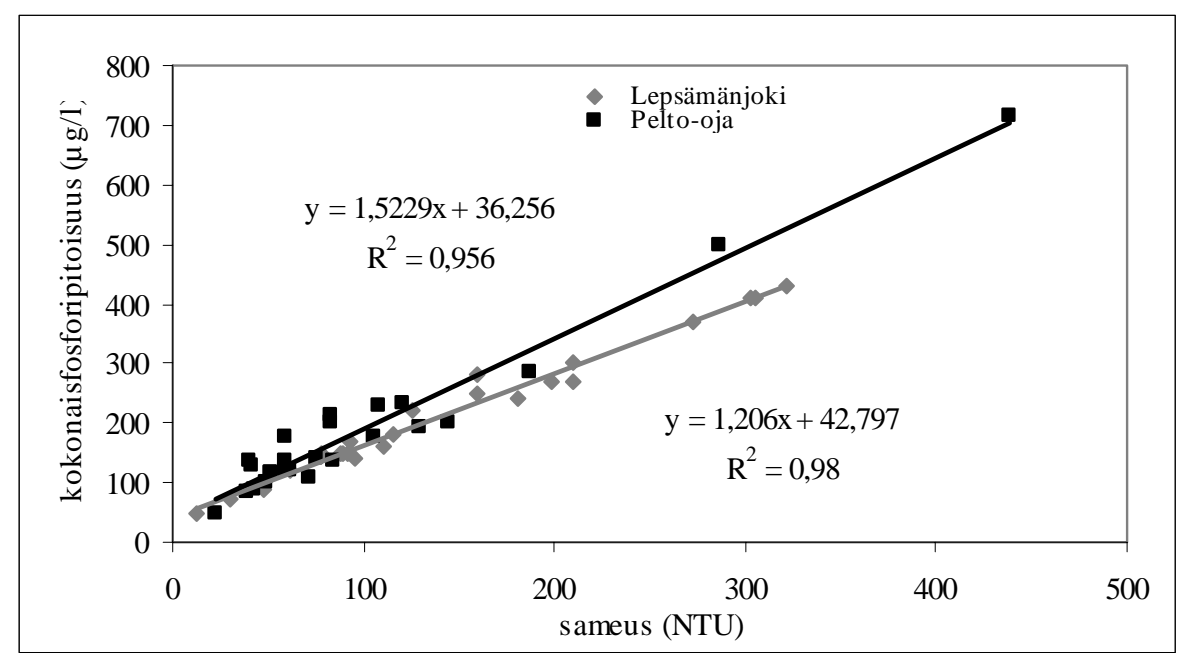

Kuva 1. Anturin mittaaman sameuden ja laboratoriossa määritetyn kokonaisfosforipitoisuuden välillä todettiin erittäin merkitsevä positiivinen korrelaatio Lepsämänjoen ja pelto-ojan aineistossa (aineisto vuodelta 2008). 
Molemmilla tutkimusalueilla on havaittu anturin mittaaman sameuden ja laboratoriossa määritetyn kokonaisfosforipitoisuuden (kuva 1) ja kiintoainepitoisuuden välillä erittäin merkitsevä positiivinen korrelaatio (Valkama ym. 2007a, Valkama ym. 2007 b). Tuntikohtainen kiintoaine- ja kokonaisfosforipitoisuus voitiin siis laskea anturin mittaaman sameuden perusteella. Virtaama laskettiin mittauspaikoille laadittujen purkautumiskäyrien ja vedenkorkeustiedon avulla.

\section{Tulokset ja tulosten tarkastelu}

\section{Automaattiseurannan tuoma hyöty}

Keväällä 2008 pelto-ojan valuma-alueella satoi huhtikuun 13.-14. päivän aikana 19 mm. Edeltävien sateiden jäljiltä märkä maa ei pystynyt imemään satanutta vettä. Tilanne johti nopean pintavalunnan syntymiseen aiheuttaen ojan virtaamaan nopean nousuvaiheen (kuva 2).

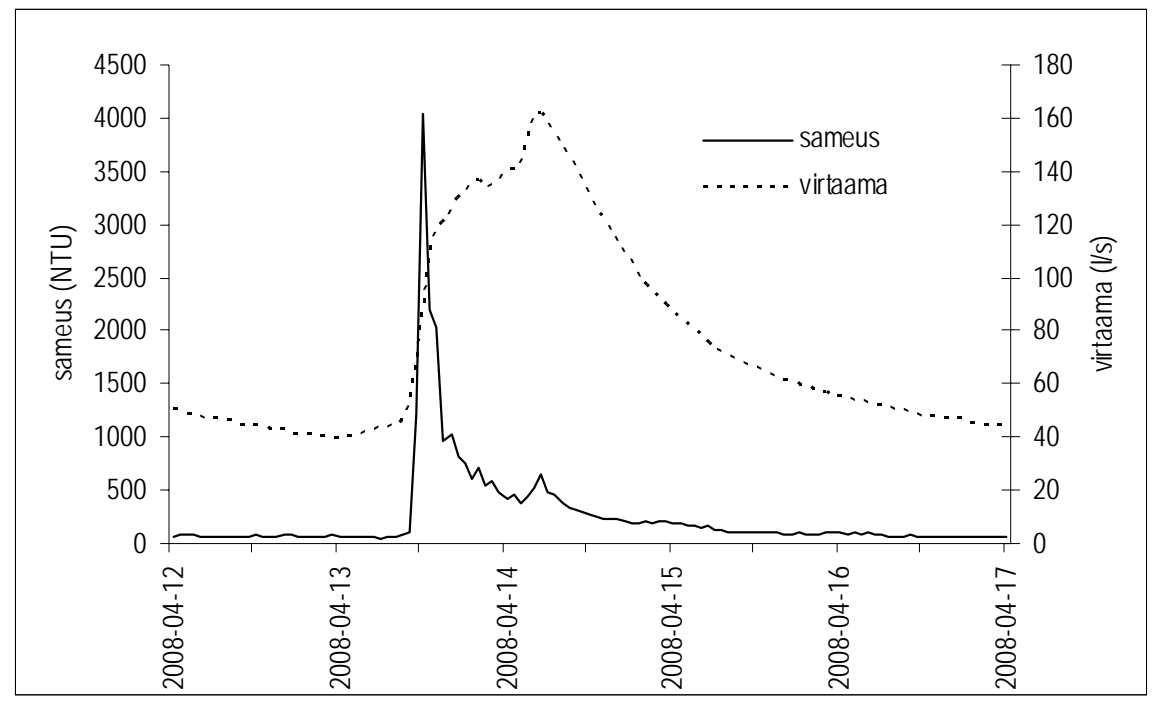

Kuva 2. Pelto-ojan sameus nousi neljässä tunnissa 80-kertaiseksi keväällä 2008

Yksittäisillä näytteillä ei päästä kiinni veden laadussa tapahtuvaan todelliseen vaihteluun. Siksi niiden avulla ei saada tarkkaa tietoa kuormituksen todellisesta määrästä tai ajoittumisesta. Tutkimuksessa havaitut kokonaisfosforipitoisuudessa tapahtuvat muutokset olivat niin nopeita, että näytteenottohetken siirtäminen muutamalla tunnilla eteenpäin voi muuttaa tulosta monikymmenkertaisesti. Yksittäisten näytteenottoajankohtien perusteella tehtävät päätelmät ravinnekuormista oikaisevatkin laskelmia liikaa. Taulukossa 1 on vertailtu Lepsämänjoesta ja pelto-ojasta ylivirtaamajaksojen ajalta automaattidatan perusteella ja yksittäisten vesinäytteiden perusteella laskettuja kokonaisfosforikuormia.

Taulukko 1. Lepsämänjoen ja pelto-ojan kokonaisfosforikuormat ylivirtaamajaksoilla 2005-2007 laskettuna automaattidatan perusteella ja yksittäisten vesinäytteiden perusteella.

\begin{tabular}{|c|c|c|c|c|}
\hline \multirow[t]{2}{*}{$\begin{array}{c}\text { Tutkimus- } \\
\text { jakso }\end{array}$} & \multicolumn{2}{|c|}{$\begin{array}{l}\text { kokonaisfosforikuorma } \\
\text { kg/tutkimusjakso } \\
\text { anturidatan perusteella }\end{array}$} & \multicolumn{2}{|c|}{$\begin{array}{l}\text { kokonaisfosforikuorma } \\
\text { kg/tutkimusjakso } \\
\text { näytteiden perust. }\end{array}$} \\
\hline & \begin{tabular}{|l|} 
pelto-oja \\
\end{tabular} & Lepsämänjoki & pelto-oja & Lepsämänjoki \\
\hline syksy 2005 & 0,5 & 16 & 0,5 & 16 \\
\hline kevät 2006 & 55 & 182 & 110 & 138 \\
\hline syksy 2006 & 9 & 78 & 19 & 199 \\
\hline kevät 2007 & 21 & 250 & 26 & 225 \\
\hline
\end{tabular}

Yksittäisten näytteiden perusteella laskettuihin kuormiin saattaa yhdellä suurella pitoisuudella olla kokonaislaskentajakson kannalta hyvin suuri merkitys. Toisaalta yksittäisillä näytteillä ei välttämättä 
osuta nopeisiin pitoisuushuippuihin ja siten lasketusta kuormasta saadaan todellista pienempi. Koska tässä tutkimuksessa näytteenotto pyrittiin ajoittamaan suurimpien pitoisuuksien aikaan, korostuvat ne laskentajaksoissa nostaen yksittäisten näytteiden perusteella laskettavia fosforikuormia.

\section{Talvien leudontumisen vaikutus kuormitukseen}

Lepsämänjoen pitkän mittaussarjan aikana valuma-alueella on koettu poikkeuksellisen leutoja talvia. Termisen talven toteutuessa kuormitus on Lepsämänjoen yläosan valuma-alueella vähäistä. Vuonna 2007 terminen talvi kesti tutkimusalueella noin puolitoista kuukautta pienentäen fosforikuormaa tänä aikana. Talvella pintavaluntojen estyminen, routa, jää ja lumipeite estävät eroosiota kasvipeitteettömilläkin pelloilla. Talvi 2007-2008 oli lauha ja sateinen luoden olosuhteet hankalaksi eroosion ja ravinnekuormituksen kannalta. Vuoden kokonaiskuorma kasvoi hyvin suureksi lokakuun ja marraskuun sateiden ja lauhan alkutalven takia (kuva 3).

Talvella 2008 lämpimät jaksot ja lyhyet pakkasjaksot vuorottelivat Lepsämänjoen valumaalueella. Tyypillistä oli maahan sataneen lumen sulaminen seuraavan lämpimän jakson aikana tulleen vesisateen yhteydessä. Vesisateen sulattaman lumen aiheuttama pintavalunta on pahempi eroosion aiheuttaja kuin vastaavan vesisateen vaikutus yksinään. Etenkin savisella alueella lumen sulamisveden aiheuttama ionivahvuuden heikkeneminen vähentää kolloidien välistä koheesiovoimaa ja voimistaa niiden erodoitumista pintavalunnan mukaan.

Lepsämänjoen kokonaisfosforikuorma oli vuonna 2008 noin $2500 \mathrm{~kg}$. Kuormitus muodostui pääasiassa tammikuun ja huhtikuun, sekä lokakuun ja joulukuun välisenä aikana (kuva 3). Aikaisempina vuosina kuormitus on jakautunut lyhyemmille jaksoille. Vuonna 2006 mittaukset alkoivat huhtikuussa kevättulvan aikana, joten koko vuoden kuormaa ei ole tiedossa.

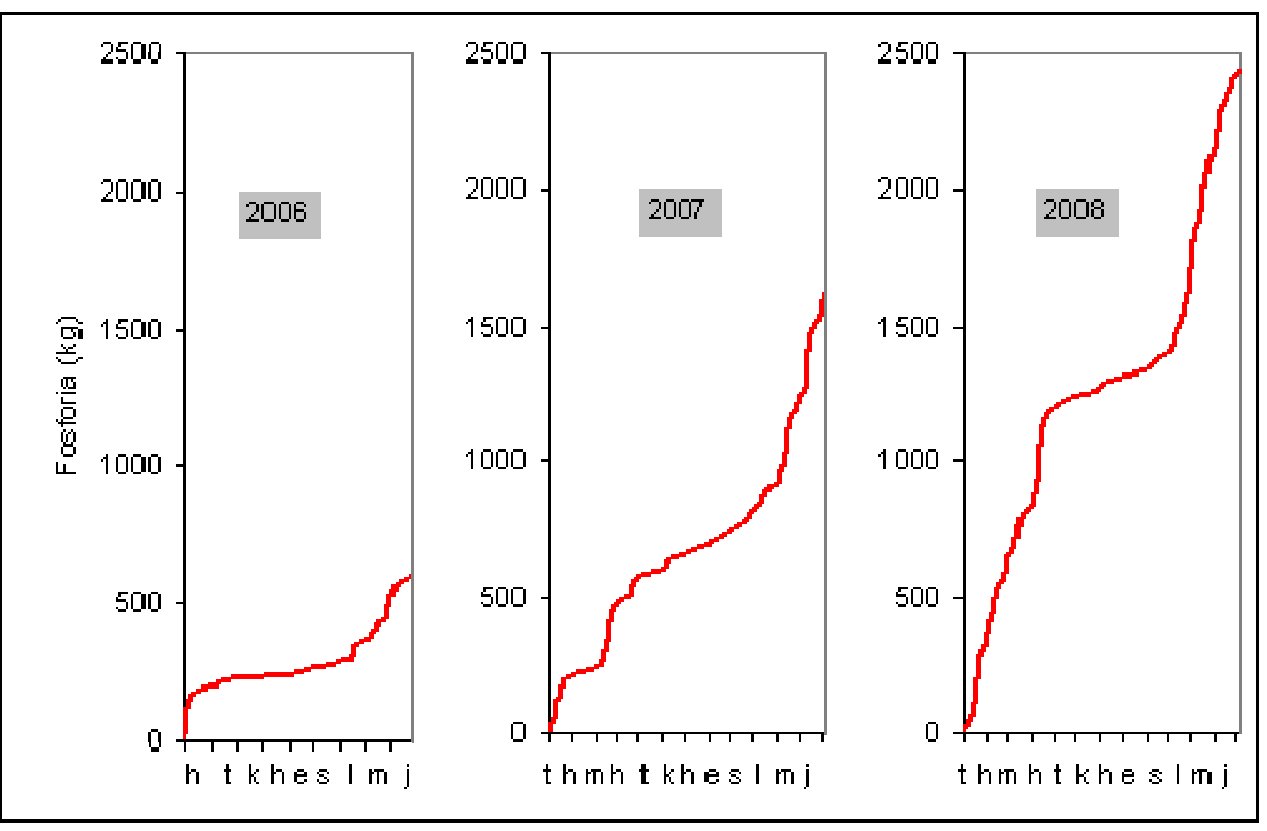

Kuva 3. Lepsämänjoen tutkimusaseman vuotuiset fosforin summakuormat.

Lähitulevaisuuden ilmastoa ennustavien skenaarioiden mukaan eteläisen Suomen talvet tulevat leudontumaan ja muuttumaan sateisemmiksi lisäten talviaikaista valuntaa (IPCC 2007). Talvet 20062007 ja 2007-2008 vastasivat olosuhteiltaan tällaisia talvia. Siten niiden perusteella voidaan arvioida ilmaston lämpenemisen seurauksena hajakuormituksessa tapahtuvia muutoksia. Leutojen talvien aikainen ravinne- ja kiintoainekuormitus Lepsämänjoen peltovaltaisella valuma-alueella on hyvin voimakasta verrattuna termisen talven aikaiseen kuormitukseen. 


\section{Kuormituksen muodostuminen}

Merkittävä osa fosforikuormituksesta muodostuu Lepsämänjoessa ja pelto-ojassa hyvin nopeina kuormituspiikkeinä tulvan nousuvaiheessa ja nitraattikuorma taas virtaaman laskuvaiheessa. Kuvasta 4 nähdään miten kokonaisfosforipitoisuuden ja nitraattipitoisuuden maksimiarvot ajoittuivat eri tavalla suhteessa virtaamaan Lepsämänjoessa keväällä 2007. Virtaaman ja pitoisuuden välisestä viiveestä käytetään nimitystä hysteresis.

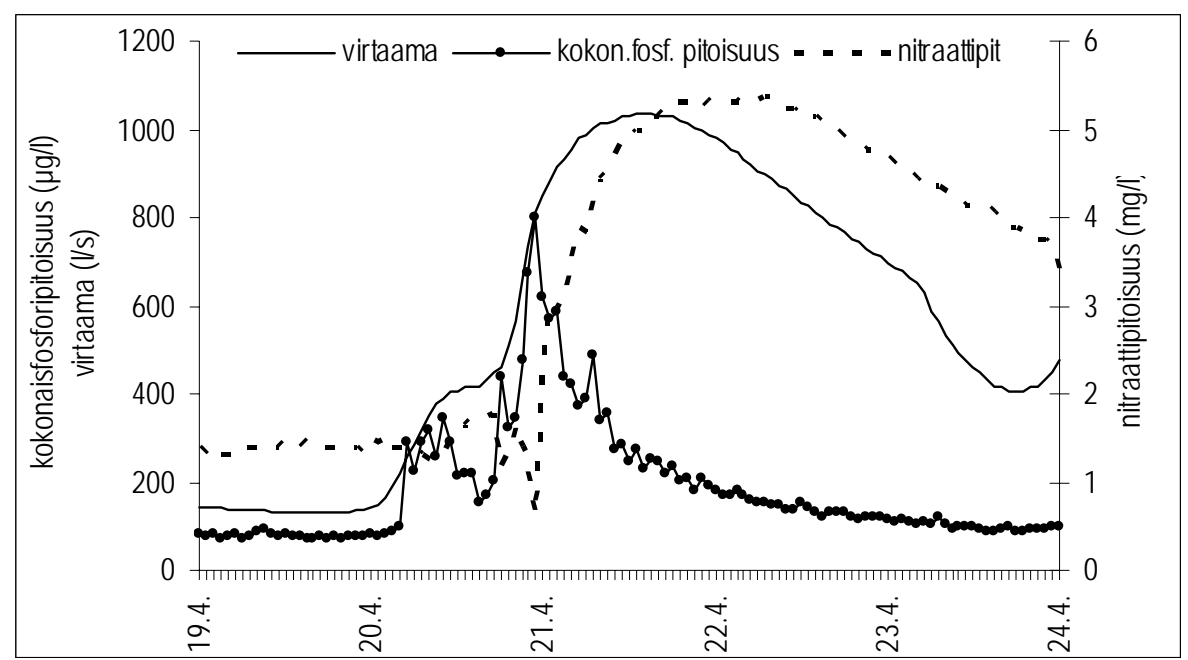

Kuva 4. Kokonaisfosforipitoisuuden ja nitraattipitoisuuden vaihtelu suhteessa virtaamaan Lepsämänjoessa keväällä 2007.

Hysteresis-nimitystä on yleensä käytetty kuvaamaan virtaamahuipun ja kiintoainepitoisuuden maksimin välistä viipymää (Seuna \& Vehviläinen 1986). Kiintoainepitoisuuden huippu voi esiintyä ennen virtaamahuippua tai sen jälkeen riippuen esimerkiksi kiintoaineen alkuperästä (Lawler ym. 2006). Kuvan 5 kaltaisesta ilmiöstä käytetään tässä tutkimuksessa nimitystä kokonaisfosforin positiivinen hysteresis. Vuoden 2005 syksyllä alkaneiden Lepsämänjoen mittausten aikana kiintoainepitoisuuden ja kokonaisfosforipitoisuuden kohdalla vallitsevana on ollut positiivinen hysteresis. Sen on ajateltu johtuvan tulvan nousuvaiheessa uoman pohjaan kerääntyneen kiintoaineen liikkeelle lähdöstä (Tikkanen ym. 1985; Zabaleta ym. 2007). Uomaan kiintoaine ja siihen sitoutunut fosfori kerääntyvät lähinnä valuma-alueen pelloilta pintavalunnan mukana, mutta myös salaojien kautta.

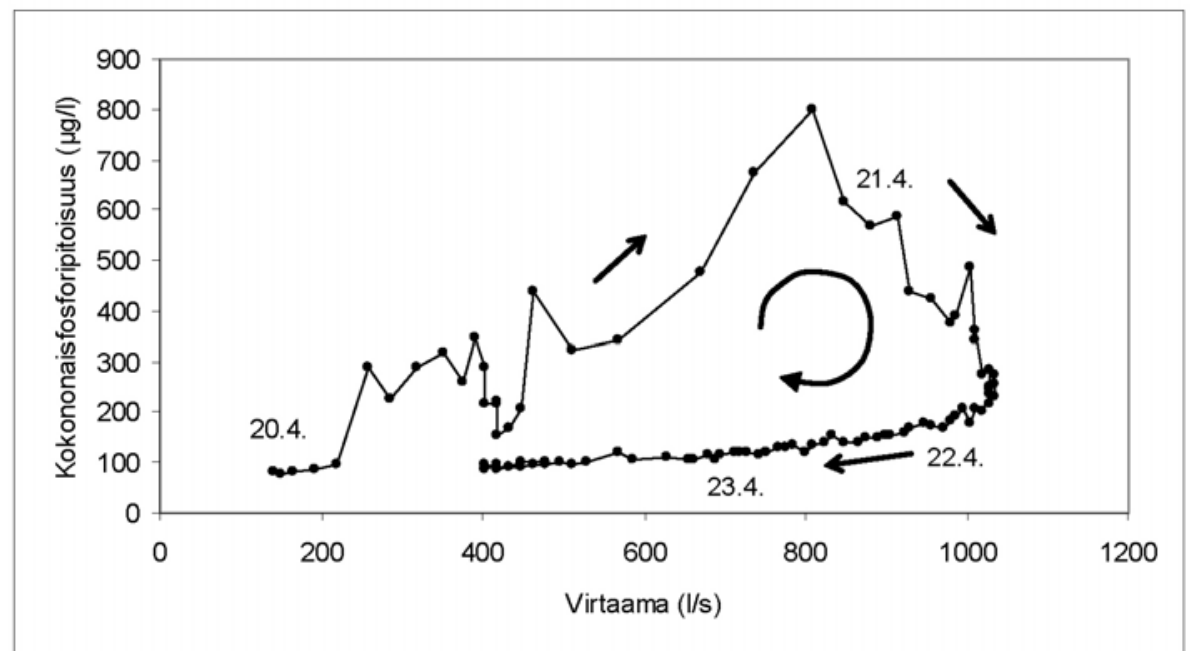

Kuva 5. Kokonaisfosforipitoisuuden maksimin ajoittuminen virtaamahuippua ennen, johtaa hysteresis - kuvaajan kiertymiseen myötäpäivään. 


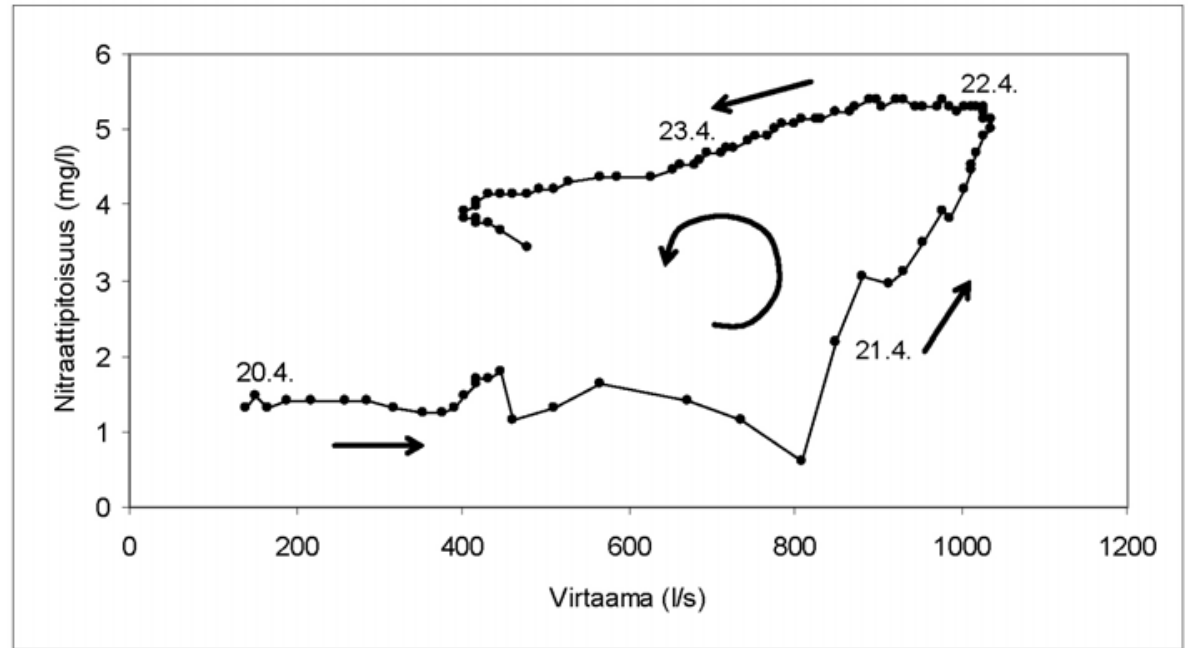

Kuva 6. Nitraattipitoisuuden maksimin ajoittuminen virtaamahuipun jälkeen johtaa hysteresis - kuvaajan kiertymiseen vastapäivään.

Nitraattikuormitus muodostuu Lepsämänjoessa eri tavalla kuin fosforikuorma. Nitraattipitoisuuden maksimiarvon ja virtaaman maksimin välinen viive aiheuttavat nitraattipitoisuuden hysteresissilmukan kiertymiseen vastapäivään (kuva 6). Ilmiöstä käytetään tässä tutkimuksessa nimitystä nitraatin negatiivinen hysteresis. Viive virtaaman ja pitoisuuden välillä viittaa nitraattikuorman tulevan hitaammin uomaan kuin fosforin. Maatalousvaltaisella valuma-alueella onkin todennäköistä, että nitraatti tulee uomaan salaojien kautta, jolloin veden suotautuminen maakerroksen läpi salaojasyvyyteen ja edelleen salaojia pitkin uomaan aiheuttaa havaitun viiveen. Pintavalunnan mukana huuhtoutuu vain pieni osa nitraatista (Tan ym. 2002).

\section{Johtopäätökset}

Maataloudesta tuleva hajakuormitus vaihtelee voimakkaasti hydrologisten olosuhteiden mukaan. Tällöin näytteenoton tiheydellä ja ajoittumisella on hyvin suuri merkitys kiintoaine- ja ravinnekuormien arvioinnissa. Yksittäisillä vesinäytteillä veden laadussa tapahtuvat nopeat vaihtelut jäävät havaitsematta ja siten niiden perusteella tehtävät kuormituslaskelmat voivat antaa hyvin virheellisen kuvan kuormituksesta. Automaattisilla, jatkuvatoimisilla mittausantureilla nopeatkin veden laadussa tapahtuvat muutokset tulevat esiin ja niihin perustuvat kuormituslaskelmat antavat ravinnekuormasta tarkemman kuvan.

Jos ilmastonmuutos merkitsee eteläisen Suomen talvien leudontumista ja sademäärien kasvua, merkitsee se peltoviljelystä tulevan kuormituksen kasvua Lepsämänjoen kaltaisilla valuma-alueilla. Kuormituksen painopiste siirtyy talviaikaan ja kevättulvien merkitys vähenee ohenevan tai kokonaan puuttuvan lumipeitteen myötä. Kokonaiskuormitus kasvaa talviaikaisten sademäärien lisääntymisen myötä. Eroosioon vaikuttavien tekijöiden voimistuminen juuri kasvukauden ulkopuolella on hyvin ongelmallista, koska kasvillisuuden merkitys eroosion vähentämisessä on todettu hyvin tärkeäksi. Entistä merkittävämpään rooliin nouseekin koko viljelypinta-alalla tehtävät eroosion vähennyskeinot ja erityisesti talviaikainen kasvipeitteisyys.

Automaattisten mittausantureiden käyttö veden laadun seurannassa on tuonut paljon uutta tietoa pienissä virtavesissä tapahtuvista ravinne- ja kiintoainekulkeutumista. Jatkuvatoiminen veden laadun seuranta on osoittautunut erinomaiseksi välineeksi tutkittaessa virtavesien kuormituksen lyhyen aikavälin dynamiikkaa ja tarkennettaessa valuma-alueelta tulevia kiintoaine- ja ravinnekuormitusmääriä. Automaattisten mittausantureiden käyttö on lisääntynyt ja lisääntyy tulevaisuudessa paljon eri puolilla Suomea, niin tutkimus- kuin seurantakäytössäkin. 


\section{Kirjallisuus}

IPCC. 2007. Climate Change 2007: Synthesis Report. 52 p. Available: http://www.ipcc.ch/pdf/assesmentreport/ar4/syr/ar4_syr.pdf

Leinonen, A. 1992. Vedenlaatu ja ravinteiden hajakuormitus Tourujoen vesistöalueella 1989-1991. Vesi- ja kuormittajien vesistövaikutusten arviointi. Vesi- ja ympäristöhallituksen monistesarja 464. 52 s.

Lehtinen, K., Koponen, J. \& Frisk, T. 1993. Keski-Päijänteen virtaus- ja vedenlaatumallisovellus: fosfori kuormittajien vesistövaikutusten arviointi. Vesi- ja ympäristöhallituksen monistesarja 464. 52 s.

Nykänen, I. 1991. Tainionvirran hajakuormitustarkastelu. Mikkelin vesi- ja ympäristöpiiri 4.16 s. ympäristöhallituksen monistesarja 379. $146 \mathrm{~s}$.

Räike, A., Granlund, K. \& Ekholm, P. 2004. Nutrient load from agricultural land and its effects in surface waters - evaluation based on monitoring data. Teoksessa Turtola, E. \& Lemola, R. (toim.): Maatalouden ympäristötuen seuranta MYTVAS 2. Osahankkeiden 2-7 väliraportit 2000-2003. Maa- ja elintarviketalous 59, 98109.

Seuna, P. \& B. Vehviläinen 1986. Eroosio ja kiintoaineen kulkeutuminen. Teoksessa Mustonen, S. (toim.): Sovellettu hydrologia, 226-255. Vesiyhdistys ry, Helsinki.

Särkelä, A., Lahti, K., Vahtera, H., Penttilä, S. \& Ahtela, I. 2006. Automaattinen veden laadun seuranta avuksi hajakuormituksen arviointiin. Vesitalous 4/2006, 20-25.

Tan, C. S., C.F. Drury, W.D. Reynolds, P.H. Groenevelt \& H. Dadfar 2002. Water and nitrate loss through tiles under a clay loam soil in Ontario after 42 years of consistent fertilization and crop rotation. Agriculture, Ecosystems and Environment 93, 121-130.

Tikkanen, M., Seppälä, M. \& Heikkinen, O. 1985. Environmental properties and material transport of two rivulets in Lammi, southern Finland. Fennia 163: 2, 217-282.

Valkama, P., Lahti, K. \& Särkelä, A. 2007a. Fosforikuormituksen arviointi pelto-ojan valuma-alueelta ylivirtaama-aikoina. Vesitalous 5/2007, 30-34.

Valkama, P., Lahti, K. \& Särkelä, A. 2007b. Automaattinen veden laadun seuranta Lepsämänjoella. Terra 119: 3-4, 195-206.

Valkama, P., K. Lahti \& A. Särkelä 2008. Fosfori- ja typpikuormituksen muodostuminen Lepsämänjoessa kevät- ja syystulvatilanteissa. Vesitalous 5/2008: 26-30.

Zabaleta, A., M. Martinez, J. A. Uriarte \& I. Antigüedad 2007. Factors controlling suspended sediment yield during runoff events in small headwater catchments of the Basque Country. Catena 71, 179-190. 